\section{Commentary: The tale of technology: Extending the boundaries of thoracic surgery}

\section{Scott J. Swanson, MD}

The case report by Iriarte and colleagues in this issue of Techniques describes a right-sided approach using robotic technology and a small left-sided endobronchial tube to resect a small proximal left main stem low-grade tumor. ${ }^{1}$ This is well described, and the accompanying video is clear. There is no question that technology is making difficult surgery more feasible and safer, and the authors present an example of just such a situation. One must emphasize that these cases are very difficult to do whether using advanced minimally invasive technology or an open approach. It is imperative that the surgeon be very familiar with the disease process, the steps of the operation, the potential pitfalls, and how to manage them in real time. It must be emphasized that the principles of the operation should never be compromised by the approach chosen. For example, if during a videoassisted thoracoscopic surgery or robotic sleeve resection, as in this case, where the endobronchial tube is left in place, the surgeon cannot visualize or place the sutures perfectly or if the resection of the tumor might be compromised, one must have an intraoperative plan to manage this. It might be intermittent ventilation with the tube pulled back and cross-table ventilation, as the authors suggest, or converting
From the Division of Thoracic and Cardiac Surgery, Department of Surgery, Brigham \& Women's Hospital, Boston, Mass.

Disclosures: Dr Scott J. Swanson discloses relationships as a consultant for Ethicon and Medtronic.

The Journal policy requires editors and reviewers to disclose conflicts of interest and to decline handling or reviewing manuscripts for which they may have a conflict of interest. The editors and reviewers of this article have no conflicts of interest.

Received for publication Oct 20, 2021; revisions received Oct 20, 2021; accepted for publication Oct 26, 2021; available ahead of print Oct 29, 2021.

Address for reprints: Scott J. Swanson, MD, Division of Thoracic and Cardiac Surgery, Department of Surgery, Brigham \& Women's Hospital, 75 Francis St, Boston, MA 02115 (E-mail: sjswanson@bwh.harvard.edu).

JTCVS Techniques 2021;10:577

2666-2507

Copyright (C) 2021 The Authors. Published by Elsevier Inc. on behalf of The American Association for Thoracic Surgery. This is an open access article under the CC BY-NCND license (http://creativecommons.org/licenses/by-nc-nd/4.0/).

https://doi.org/10.1016/j.xjtc.2021.10.055

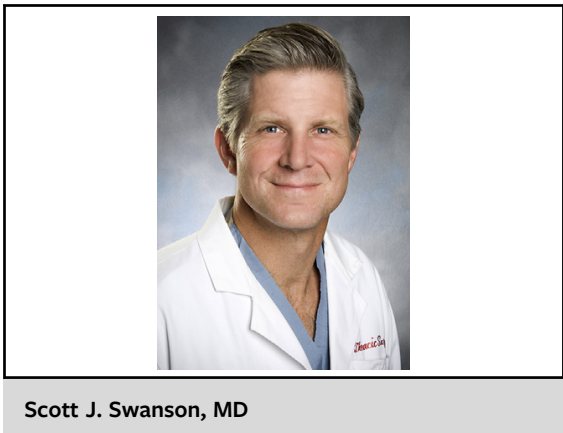

CENTRAL MESSAGE

Technology, when used correctly, helps extend the boundary of thoracic surgery.

to an extracorporeal membrane oxygenation plan, which was also mentioned. The authors are to be congratulated on this case. We need to keep advancing techniques in terms of safety and extending the boundaries of what is resectable using new technology. In this way, we can fulfill our surgical mission, which is to cure or treat more people with the least morbidity and mortality possible.

\section{Reference}

1. Iriarte F, Abbas AE, Petrov R, Bakhos CT, Su S. Right transthoracic approach for robotic left main stem bronchus sleeve resection. J Thorac Cardiovasc Surg Tech. 2021;10:572-4. 